\title{
Load-based Exergetic Assessment of an Offshore Thermal Power Plant in an Equatorial Environment
}

\author{
Sidum Adumene \\ Correspondence: Sidum Adumene, Department of Marine Engineering, Rivers State University of Science and \\ Technology, Port Harcourt, Nigeria.
}

Received: October 28, 2015

doi:10.11114/set.v3i1.1177
Accepted: November 10, 2015 Online Published: November 19, 2015

URL: http://dx.doi.org/10.11114/set.v3i1.1177

\begin{abstract}
The Load-based exergetic assessment of a thermal power plant for offshore utilization was carried out. The gas turbine systems were split into sub-systems and simplified into control volume to show inflow and outflow of exergy at different loading. The operating parameters of the plant were monitored for 12 months through human machine interface (HMI), and the data collected were used with thermodynamic relations to carry out the assessment. MATLAB $7.3{ }^{\circledR}$ Software was used to evaluate the various model equations and results tabulated. The results show that for every $1 \%$ drop in the operational load, the thermal efficiency and exergy efficiency drop by $0.17 \%$ and $0.25 \%$ respectively. It further shows that there is about $0.006 \%$ decrease in fuel consumption under the same conditions, and at $44 \%$ loading the system has the highest percentage of exergy loss of about $21.3 \%$. This means that as the operational load decrease, the percentage exergy loss increase proportionally. Enormous exergy is lost in the exhaust system due to absence of heat recovery steam generator. The assessment established that the components of the power plant degrade in the quality of exergy and performance at different loading of the plant due to mechanical loss and irreversibility.
\end{abstract}

Keywords: thermal plant, exergy assessment, efficiency, operational load, irreversibility

\section{Introduction}

The advances in gas turbine manufacturing and performance over the years had helped to solve critical energy need of humanity. Gas turbine converts the chemical energy of fuel into mechanical energy using air as the medium of conversion. The resulting mechanical energy can be used to drive many types of rotating equipment like alternators, pumps and compressor. The development of science and technology has enhanced our ability to harness energy and utilize it rationally. The international energy agency reports that fossil fuels supply over $85 \%$ of the world's commercial energy, account for $65 \%$ of the world's electricity and $97 \%$ of the energy for transportation. This shows that the world's energy demand tilt towards fossil fuel with little attention to other energy resources.

In recognition of this energy need, Sureh et al. (2006) remarked that "power plants should be operated in the most efficient manner to check the rate of depletion of fossil fuel reserves". To achieve this, there is need for periodic performance evaluation of the power plant using a load-based exergetic technique. Exergy have been viewed by different researchers as available energy to be a quantitative measure of the mechanical work lost in any real thermodynamic system as a result of irreversibility in the system. Kwambai (2005) and Hermann (2005) view exergy as a "work potential" of a system. Their view was drawn from the fact that any system which is at a temperature, pressure or chemical composition above that of its surroundings is not in equilibrium and has a potential to do work. Therefore, when a system is at a state of equilibrium with its environment, there would be no work transfer, and its exergy is equal to zero.

Kotas (1995) states that "the exergy of a steady stream of matter is equal to the maximum amount of work obtainable when the stream in brought from its initial state to the dead state by processes during which the stream may interact only with the environment". Exergy corresponds to the "useful" part of energy. Whereas energy is conserved with respect to the first law of thermodynamics, exergy destroyed or degraded with respect to the second law of thermodynamic and helps to locate the wasteful uses of exergy in energy conversion system.

In the past decades, exergy related studies have received considerable attention from various discipline ranging from mechanical engineering to chemical engineering from environmental engineering to ecology, and other fetch of engineering as well as the physical science. Consequent upon this, there is global attention on exergy studies (Dincer \& 
Cengel 2001). The importance of exergy analysis in performance evaluation of energy systems has been demonstrated in many optimization studies of the power plants. Lebele-Alawa \& Asuo (2011) in their work showed that the highest exergy loss occur in the combustion chamber with a magnitude of about 22.18MW for a gas turbine within the tropical zone. Ertesvag et al (2004) demonstrated the effects of process parameter such as increase gas turbine pressure ratio, increase turbine inlet temperature and increase steam-turbine-inlet temperature, on the exergy performance of a gas turbine combined cycle power plant with pre-combustion $\mathrm{Co}_{2}$ capture. They further stated that a substantial exergy loss occurred in a natural gas fired turbine plant compared to using a hydrogen rich fuel. In the work of Kwambai (2005), steam transmission units, turbines, condensers and gas ejectors were identified as sub-systems where exergy losses occurred. He added that the highest exergy loss occurred in the condenser due to the limitations of the wetness of the exhaust system.

Verkhivker \& Kosoy (2004) identified combustion process, heating of working fluid and heat transfer in the heat exchangers as the thrice principal processes that cause destruction of exergy in a power generation cycle. Anheden (2002) used the chemical looping combustion technique to investigate the possibilities of reducing exergy lon in the combustion process .of a thermal plant and found that the use of nickel oxide as an oxidant instead of oxygen in the air results to decrease in combustion exergy destruction and increase power generation efficiency. Ebadi and Gorgi -Bandy (2005) carried out all exergetic analysis on 116MW gas turbine plant at Mahshahr-Iran, and found that there is appreciable increase in exergetic efficiency due to increasing turbine inlet temperature. Sue and Chuang (2002) examined the effect of partial load on exergy efficiency of combine cycle power plant with the variation of compressor inlet and of the fuel temperature. The results show that the power output of the gas turbine increase as the inlet air temperature decrease and at 50\% load, the exergy load in a CCPP was three times that of $100 \%$ load due to lower steam pressure in the HRSG. Hence, the importance of this source is use to determine the thermodynamic performance and improvement of the said power plant. It therefore investigates the effects of irreversibility's on power plant components at each prevailing operational condition of the power plant.

The study area is the South-South zone of Nigeria which lies between latitudes $4^{0} \mathrm{~N}$ and $6^{\circ} \mathrm{N}$, and longitude $5^{0} \mathrm{E}$ and $8^{0} \mathrm{E}$. The vegetation of the area is equatorial rain forest. There are basically two seasons- the wet (April to September) and the dry (October to March). However, rain fall throughout the year. The mean annual rainfall in the area is between $200 \mathrm{~mm}$ in the North and $400 \mathrm{~mm}$ in the South of the region. The mean daily temperature of the region varies slightly from $27^{\circ} \mathrm{C}$ to $30^{\circ} \mathrm{C}$ all the year round. The maximum and minimum temperatures are $40^{\circ} \mathrm{C}$ and $20^{\circ} \mathrm{C}$ respectively. The relative humidity varies between a minimum of 50\% and a maximum of $90 \%$ (Lebele-Alawa \& Asuo 2011, Lebele-Alawa \& Jo-Appah 2015). Adumene et al. (2015) present that a reduction in the ambient temperature of a gas turbine plants within the tropical environment from $31^{\circ} \mathrm{C}$ to $18^{\circ} \mathrm{C}$ improved the power output (energy performance) by about $0.78 \%$.

This research considered a load-based exergy assessment across the components of the thermal plant. This evaluates the exergetic degradation rate at different operating condition and loading in the sub-system of the power plant. The assessment was carried out between $40 \%$ - 75\% loading of the plant considering the prevailing operating environment.

\section{Material and Methods}

\subsection{Theoretical Formulation}

The MS5001 gas turbine plant of 21.6MW capacity operating on an open cycle was used as the test engine for about 12 months. The methodology adopted was designed to produce facts about the behavior of the plant, and to determine those factors that influence the exergetic thermodynamic assessment within the tropical environment. MATLAB 7.3 ${ }^{\circledR}$ (Mathworks USA) was used to evaluate the equations. Thermodynamics properties such as temperature, pressure, mass flow, and turbine inlet temperatures are crucial in this research because their behavior affect every other parameter in the analysis.

In the data collection and treatment, I considered the mean values of daily parameters by the use of statistical method.

\subsubsection{Exergy Balance for a Thermodynamic System}

Real natural gas fired power plants are steady flow open circuit systems in which fuel and oxidant (usually air) are supplied to the combustor of the plant and the products of combustion are exhausted to the atmosphere. The general control volume for such thermodynamic system is shown below. 


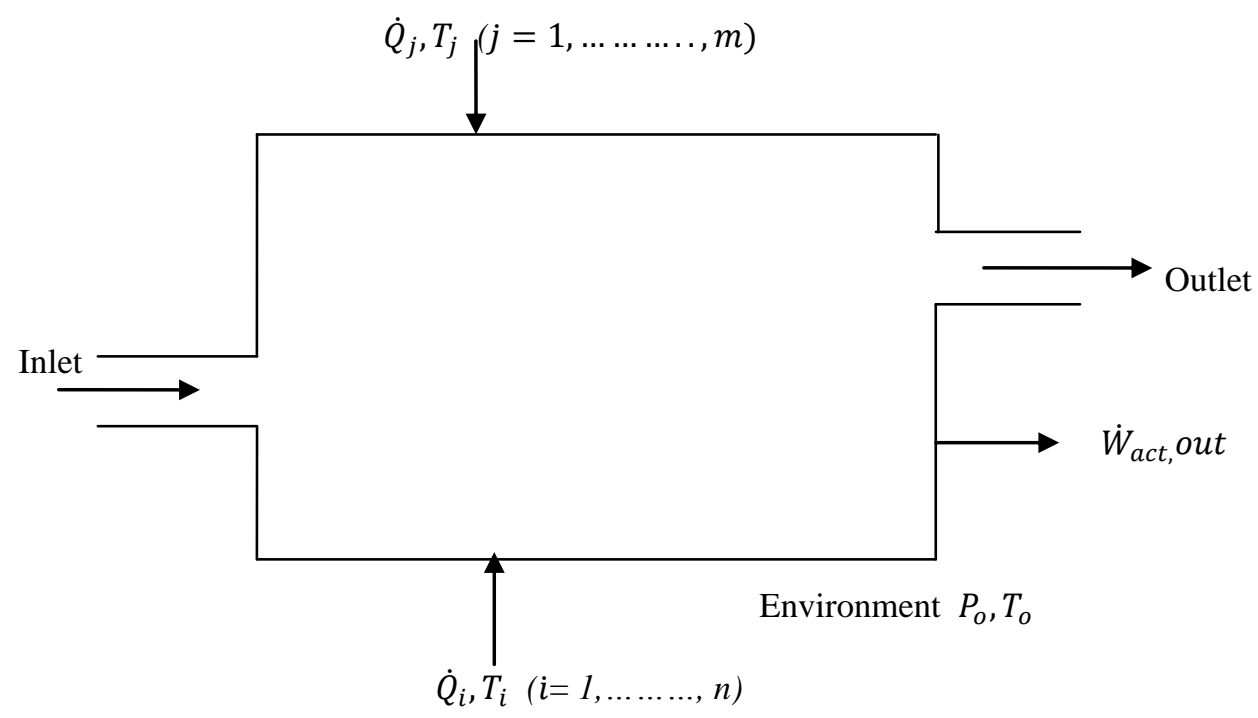

Figure 1. Control Volume with Exergy Inflow and Outflow

The first law of thermodynamic for the control volume can be written as

$$
\frac{d E_{c r}}{d t}=\dot{m}_{i}\left(h_{i}+\frac{V_{i}^{2}}{2}+g Z_{i}\right)-\dot{m}_{e}\left(h_{i}+\frac{V_{i}^{2}}{2}+g Z_{i}\right)+Q_{o}+\sum_{j=1}^{m} Q_{j}-W
$$

The second law of thermodynamic for the control volume (Dincer \& Cengel 2001) is

$$
\frac{d S_{c r}}{d t}=\dot{m}_{i} s_{i}-\dot{m}_{e} s_{e}+\frac{\dot{Q}_{o}}{T_{o}}+\sum_{j=1}^{m} \frac{\dot{Q}_{j}}{T_{j}}+\dot{S}_{g e n}
$$

Neglecting changes in kinetic and gravitational potential energy; and assuming a steady state flow process, equations 1 and 2 becomes

$$
\begin{aligned}
& 0=\dot{m}_{i} h_{i}-\dot{m}_{e} h_{e}+\dot{Q}_{o}+\sum_{j=1}^{m} \frac{\dot{Q}_{j}}{T_{j}}-\dot{W} \\
& 0=\dot{m}_{i} s_{i}-\dot{m}_{e} s_{e}+\frac{\dot{Q}_{o}}{T_{o}}+\sum_{j=1}^{m} \frac{\dot{Q}_{j}}{T_{j}}+\dot{S}_{g e n}
\end{aligned}
$$

Combining equations 3 and 4 gives

$$
\dot{W}=T_{o}\left(\dot{m}_{e} s_{e}-\dot{m}_{i} s_{i}\right)+\dot{m}_{i} h_{i}-\dot{m}_{e} h_{e}-\sum_{j=1}^{m}\left(\frac{\dot{Q}_{j}}{T_{j}}\right) T_{o}+\sum_{j=1}^{m} \dot{Q}_{j}-T_{o} \dot{S}_{g e n}
$$

But $\sum \dot{m}_{\text {in }}=\sum \dot{m}_{\text {out }}$

$$
\dot{W}=\dot{m}\left[\left(h_{i}-T_{i} s_{i}\right)-\left(h_{e}-T_{o} S_{e}\right)\right]+\sum_{j=1}^{m}\left(1-\frac{T_{o}}{T_{j}}\right) \dot{Q}_{j}-T_{o} \dot{S}_{g e n}
$$

where $\dot{W}$ is the exergy transfer by work

$\dot{m}\left[\left(h_{i}-T_{i} s_{i}\right)-\left(h_{e}-T_{o} s_{e}\right)\right]$ is the exergy transfer by mass, $\sum_{j=1}^{m}\left(1-\frac{T_{o}}{T_{j}}\right) \dot{Q}_{j}$ is the exergy transfer by heat, $T_{o} \dot{S}_{g e n}$ is the rate of exergy destruction

The term of exergy transfer by heat may be difficult to evaluate since the values of $\dot{Q}_{j}$ and $T_{j}$ are not known at every position on the boundary of the control volume. To Cushion the ensuing deficiency, Wark \& Richard (1999) suggested the replacement of the variable surface temperature $T_{j}$ by a constant boundary temperature $T_{b}$; that is 


$$
\sum_{j=1}^{m}\left(1-\frac{T_{o}}{T_{j}}\right) \dot{Q}_{j}=\left(1-\frac{T_{o}}{T_{b}}\right) \dot{Q}
$$

\subsubsection{General Expression of Exergy}

Exergy exists basically in four different forms include Kinetic exergy, potential exergy, physical exergy and chemical exergy. The total exergy flow for a stream of fluid in an energy system in the absence of Nuclear, magnetism, electricity and surface tension effects consists of these four types of exergy (Hussein et al. 2004)

Mathematically

$$
\dot{E}^{t o t}=\dot{E}^{k e}+\dot{E}^{p e}+\dot{E}^{p h}+\dot{E}^{c h e}
$$

where $\dot{E}^{k e}$ is the kinetic exergy rate, $\dot{E}^{p e}$ is the potential exergy rate, $\dot{E}^{p h}$ is the physical exergy rate, $\dot{E}^{c h e}$ is the chemical exergy rate

i. Expression for Physical Exergy

The physical exergy is expressed as

$$
\dot{E}^{p h}=\dot{m}\left[\left(h_{i}-h_{o}\right)-T_{o}\left(s_{i}-s_{o}\right)\right.
$$

ii. Expression for Chemical Exergy

The chemical exergy for gaseous mixture is derived as the sum of the exergy for the component of the mixture, and the gain in exergy due to mixing of the pure components into the stream [7]. This is expressed as

$$
\dot{E}^{\text {che }}=\sum X_{i} \dot{E}_{i}+R T_{o} \sum\left(X_{i} \operatorname{In} X_{i}\right)
$$

where $\mathrm{X}_{\mathrm{i}}$ is the mole function of component $\mathrm{i}$ in the mixture, $\mathrm{R}$ is the gas constant, $\dot{\mathrm{E}}_{\mathrm{i}}$ is the exergy of component in the mixture at the reference state.

The primary source of exergy entering the gas turbine plant is the chemical exergy from fuel (Natural gas). At standard atmospheric condition, exergy rate of fuel is expressed as

$$
\dot{E}_{f u e l}=\dot{m}_{f} \dot{E}^{\text {che }}
$$

where $\dot{E}_{\text {fuel }}$ is the exergy rate of natural gas computed using equation 10 standard chemical exergy rate, and mass flow rate of fuel.

\subsubsection{Exergy Balance for Plant Components}

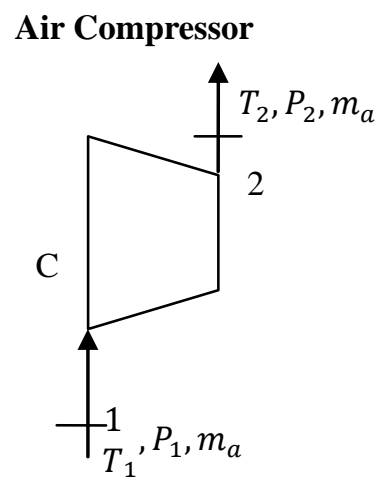

Figure 2. Flow Diagram for the Compressor

Exergy balance equation for the air compressor is given by

$$
\dot{W}_{c}=\dot{m}_{a}\left[\left(h_{2}-h_{1}\right)-T_{o}\left(s_{2}-s_{1}\right)+i_{c o m p}\right.
$$

where $i_{\text {comp }}$ is the irreversibility in the combustor which is contributed by improper mixing of air and fuel, and finite temperature difference across the combustor. 


\section{Combustion System}

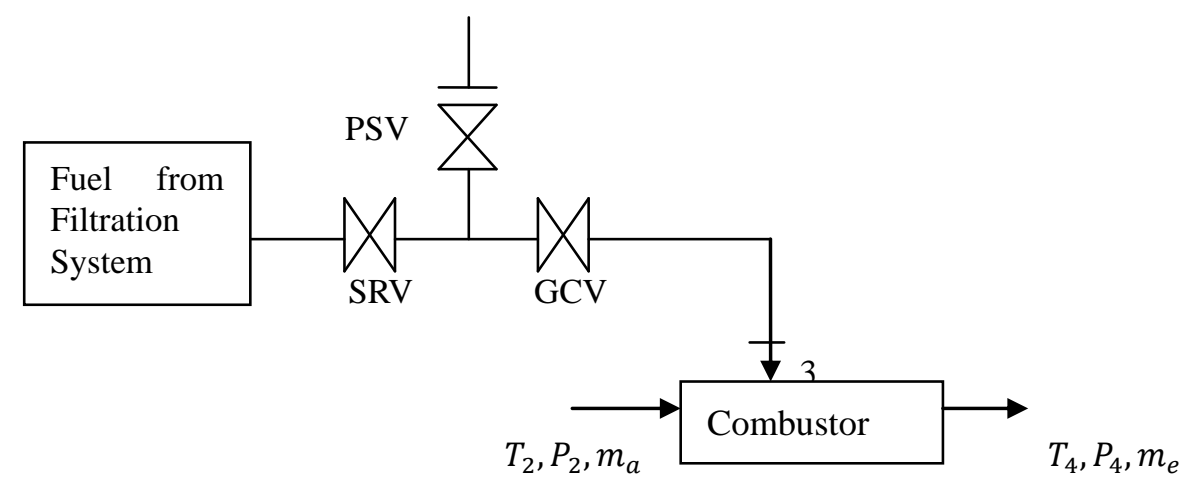

Figure 3. Flow diagram for the Combustor

From the flow diagram we have

$\dot{m}_{e}-\dot{m}_{a}=\dot{m}_{f}$

Also the exergy balance for the combustor is given by

$$
\dot{E}_{\text {fuel }}=\dot{m}_{e}\left[\left(h_{4}-h_{o}\right)-T_{o}\left(s_{4}-s_{o}\right)-\dot{m}_{a}\left[\left(h_{2}-h_{o}\right)-T_{o}\left(s_{2}-s_{o}\right)\right]+i_{\text {comp }}\right.
$$

where $i_{\text {comp }}$ is the irreversibility in the combustor which is contributed by improper mixing of air and fuel, and finite temperature difference across the combustor.

\section{Power Turbine}

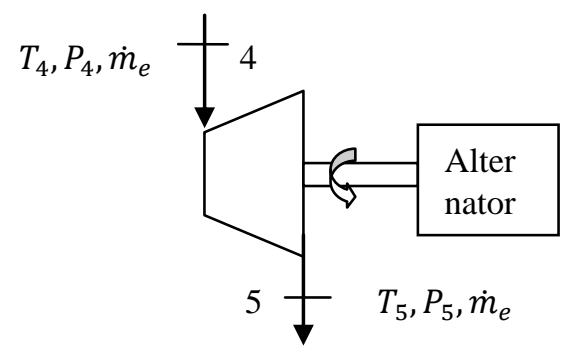

Figure 4. Flow Diagram for the Turbine

Exergy balance equation for the turbine is written as follows

$$
\dot{W}_{\text {turb }}=\dot{m}_{e}\left[\left(h_{4}-h_{5}\right)-T_{o}\left(s_{4}-s_{5}\right)+i_{\text {turb }}\right.
$$

where $i_{\text {turb }}$ is the irreversibility in the turbine which results mainly from friction.

The exergy balance for a control volume in term of input and output is given as

$$
E_{\text {input }}=E_{\text {output }}+E_{\text {destroyed }}+E_{\text {wasted }}
$$

The exergy destroyed (work lost) is obtained from the Guoy-Stodola law which state that

$$
W_{\text {lost }}=T_{o} S_{\text {gen }}
$$

This law is a further expression of irreversibility which can be obtained as the difference between mechanical work in a reversible thermodynamic process and irreversible thermodynamic process.

$$
I=W_{\text {rev }}-W_{\text {irrev }}
$$

The exergy efficiency is expressed as the ratio of the product rate exergy to fuel rate exergy of a component $\mathrm{k}$ or the ratio of exergy desired to the exergy input.

$$
\varphi=\left[\frac{\dot{E}_{\text {product }}}{\dot{E}_{\text {fuel }}}\right]_{k}=\frac{E_{\text {desired }}}{E_{\text {input }}}=1-\left[\frac{\text { Exergy destroyed }+ \text { Wasted }}{\text { Exergy input }}\right]
$$

The exergy desired is the useful exergy output and can be calculated from the exergy balance

$$
E_{\text {output }}=E_{\text {input }}-E_{\text {destroyed }}-E_{\text {wasted }}
$$

where $E_{\text {desired }}$ is the sum of useful exergy output, $E_{\text {destroyed }}$ is the exergy lost due to irreversibilities in the system, 
$E_{\text {wasted }}$ is the exergy exiting the system which has the capacity to do work, $\dot{E}_{f u e l}$ is the exergy rate of fuel injected into the system.

\section{Results and Discussion}

The parameters in Table 1 were obtained from the installation document and HMI of MS5001 gas turbine. The results of the various parameters from the thermodynamic model equations are presented in Tables 2-6.

Table 1. Design and Operational Data of the Engine

\begin{tabular}{lcc}
\hline Process Parameter & Design Specification (Max) & Operational Values (Max) \\
\hline Fuel gas pressure $($ bar) & 15 & 11.45 \\
Exhaust temperature $\left({ }^{\circ} \mathrm{C}\right)$ & 505 & 442 \\
Highest daily temperature $\left({ }^{\circ} \mathrm{C}\right)$ & 36 & 34.6 \\
Lowest daily temperature $\left({ }^{\circ} \mathrm{C}\right)$ & 16 & 24 \\
Inlet guide vane opening $(\%)$ & 90 & 87 \\
Gas control valve opening $(\%)$ & 100 & 68.5 \\
Stop ratio valve opening $(\%)$ & 100 & 54.8 \\
\hline
\end{tabular}

Table 2 . Thermodynamic properties and exergies of process stream for gas turbine system at $74 \%$ operational load.

\begin{tabular}{ccccccc}
\hline $\mathrm{M}(\mathrm{kg} / \mathrm{s})$ & $\mathrm{T}(\mathrm{K})$ & $\mathrm{P}(\mathrm{bar})$ & $\mathrm{h}(\mathrm{kJ} / \mathrm{kg})$ & $\mathrm{S}(\mathrm{kJ} / \mathrm{kgK})$ & $\begin{array}{c}\mathrm{E}^{\text {phy }} \\
(\mathrm{MW})\end{array}$ & $\mathrm{E}^{\text {fuel }}$ \\
\hline 105.30 & 305.80 & 1.013 & 306.02 & 1.7213 & 0 & 0 \\
105.30 & 592.50 & 7.30 & 599.15 & 1.829 & 23.81 & 0 \\
0.724 & 298.00 & 11.49 & - & - & 0 & 48.49 \\
106.02 & 1097.22 & 7.30 & 1157.84 & 2.5076 & 51.73 & 0 \\
106.02 & 701.00 & 1.013 & 714.36 & 2.5743 & 11.11 & 0 \\
\hline
\end{tabular}

Table 3. Thermodynamic properties and exergies of process stream for gas turbine system at $55.5 \%$ operational load.

\begin{tabular}{ccccccc}
\hline $\mathrm{M}(\mathrm{kg} / \mathrm{s})$ & $\mathrm{T}(\mathrm{K})$ & $\mathrm{P}(\mathrm{bar})$ & $\mathrm{h}(\mathrm{kJ} / \mathrm{kg})$ & $\mathrm{S}(\mathrm{kJ} / \mathrm{kgK})$ & $\mathrm{E}^{\text {phy }}(\mathrm{MW})$ & $\begin{array}{c}\mathrm{E}^{\text {fuel }} \\
(\mathrm{MW})\end{array}$ \\
\hline 102.38 & 300.60 & 1.013 & 300.8 & 1.7039 & 0 & 0 \\
102.38 & 576.50 & 7.00 & 582.38 & 1.8124 & 25.49 & 0 \\
0.61 & 298.00 & 11.49 & - & - & 55.37 & 34 \\
102.99 & 1006.86 & 7.00 & 1053.88 & 2.4208 & 12.80 & 0 \\
102.99 & 646.00 & 1.013 & 655.59 & 2.4870 & 0 \\
\hline
\end{tabular}

Table 4. Thermodynamic properties and exergies of process stream for gas turbine system at $52 \%$ operational load.

\begin{tabular}{ccccccc}
\hline $\mathrm{M}(\mathrm{kg} / \mathrm{s})$ & $\mathrm{T}(\mathrm{K})$ & $\mathrm{P}(\mathrm{bar})$ & $\mathrm{h}(\mathrm{kJ} / \mathrm{kg})$ & $\mathrm{S}(\mathrm{kJ} / \mathrm{kgK})$ & $\mathrm{E}^{\text {phy }}(\mathrm{MW})$ & $\mathrm{E}^{\text {fuel }}(\mathrm{MW})$ \\
\hline 97.88 & 297.2 & 1.013 & 297.38 & 1.6925 & 0 & 0 \\
97.88 & 567.7 & 6.80 & 573.19 & 1.8047 & 23.73 & 0 \\
0.56 & 298.0 & 11.41 & - & - & 0 & 32.32 \\
98.76 & 994.4 & 6.80 & 1045.30 & 2.4176 & 52.52 & 0 \\
98.46 & 644.0 & 1.013 & 653.47 & 2.4838 & 11.93 & 0 \\
\hline
\end{tabular}

Table 5. Thermodynamic properties and exergies of process stream for gas turbine system at $40 \%$ operational load.

\begin{tabular}{ccccccc}
\hline $\mathrm{M}(\mathrm{kg} / \mathrm{s})$ & $\mathrm{T}(\mathrm{K})$ & $\mathrm{P}(\mathrm{bar})$ & $\mathrm{h}(\mathrm{kJ} / \mathrm{kg})$ & $\mathrm{S}(\mathrm{kJ} / \mathrm{kgK})$ & $\mathrm{E}^{\text {phy }}(\mathrm{MW})$ & $\begin{array}{c}\mathrm{E}^{\text {fuel }} \\
(\mathrm{MW})\end{array}$ \\
\hline 87.64 & 298.00 & 1.013 & 298.19 & 1.6959 & 0 & 0 \\
87.64 & 558.00 & 6.30 & 563.084 & 1.7663 & 21.38 & 0 \\
0.51 & 298.00 & 11.41 & - & - & 0 & 48.49 \\
88.18 & 982.68 & 6.30 & 1026.3 & 2.4233 & 45.09 & 0 \\
88.18 & 643.00 & 1.013 & 652.41 & 2.4854 & 10.49 & 0 \\
\hline
\end{tabular}

Table 6. Exergy Audit of gas turbine sub-systems

\begin{tabular}{|c|c|c|c|c|c|c|c|c|c|c|}
\hline \multirow[t]{3}{*}{ Component } & \multicolumn{5}{|c|}{ Exergy Output (MW) } & \multicolumn{5}{|c|}{$\%$ Exergy Loss } \\
\hline & $74 \%$ & $73 \%$ & $55.5 \%$ & $52 \%$ & $44 \%$ & $74 \%$ & $73 \%$ & $55.5 \%$ & $52 \%$ & $44 \%$ \\
\hline & Load & Load & Load & Load & Load & Load & Load & Load & Load & Load \\
\hline Useful Exergy & 15.9 & 15.7 & 12 & 11.4 & 9.6 & - & - & - & - & - \\
\hline Compressor & 3.47 & 3.4 & 3.34 & 3.27 & 1.84 & 8.6 & 8.44 & 9.82 & 10.12 & 6.11 \\
\hline Combustor & 2.94 & 2.9 & 4.12 & 3.53 & 6.4 & 7.29 & 7.19 & 12.12 & 10.92 & 21.26 \\
\hline $\begin{array}{l}\text { Turbine } \\
\text { Gearbox \& }\end{array}$ & 2.16 & 2.73 & 2.05 & 2.01 & 1.63 & 5.35 & 6.75 & 6.03 & 6.22 & 5.41 \\
\hline $\begin{array}{l}\text { Generator } \\
\text { Exhaust Gas }\end{array}$ & 0.25 & 0.25 & 0.19 & $\begin{array}{l}0.18 \\
11.9\end{array}$ & 0.15 & 0.62 & 0.62 & 0.56 & 0.56 & 0.5 \\
\hline Manifold & 15.64 & 15.34 & 12.3 & 3 & 10.49 & 38.75 & 38.06 & 36.18 & 36.91 & 34.84 \\
\hline
\end{tabular}


Table 7. Exergy Performance Assessment of the Power Plant

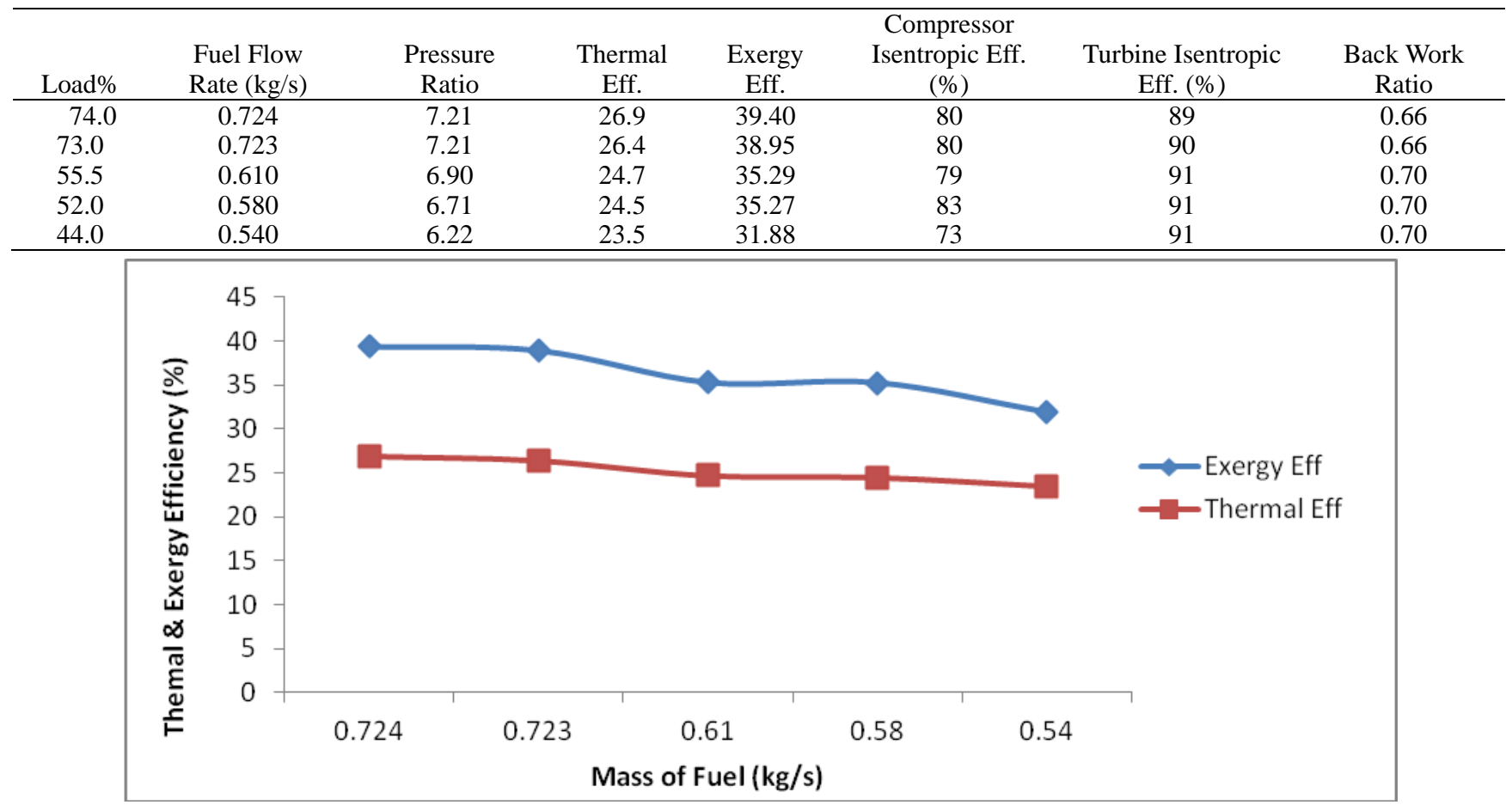

Figure 5. Thermal and Exergy Efficiency against Mass of Fuel

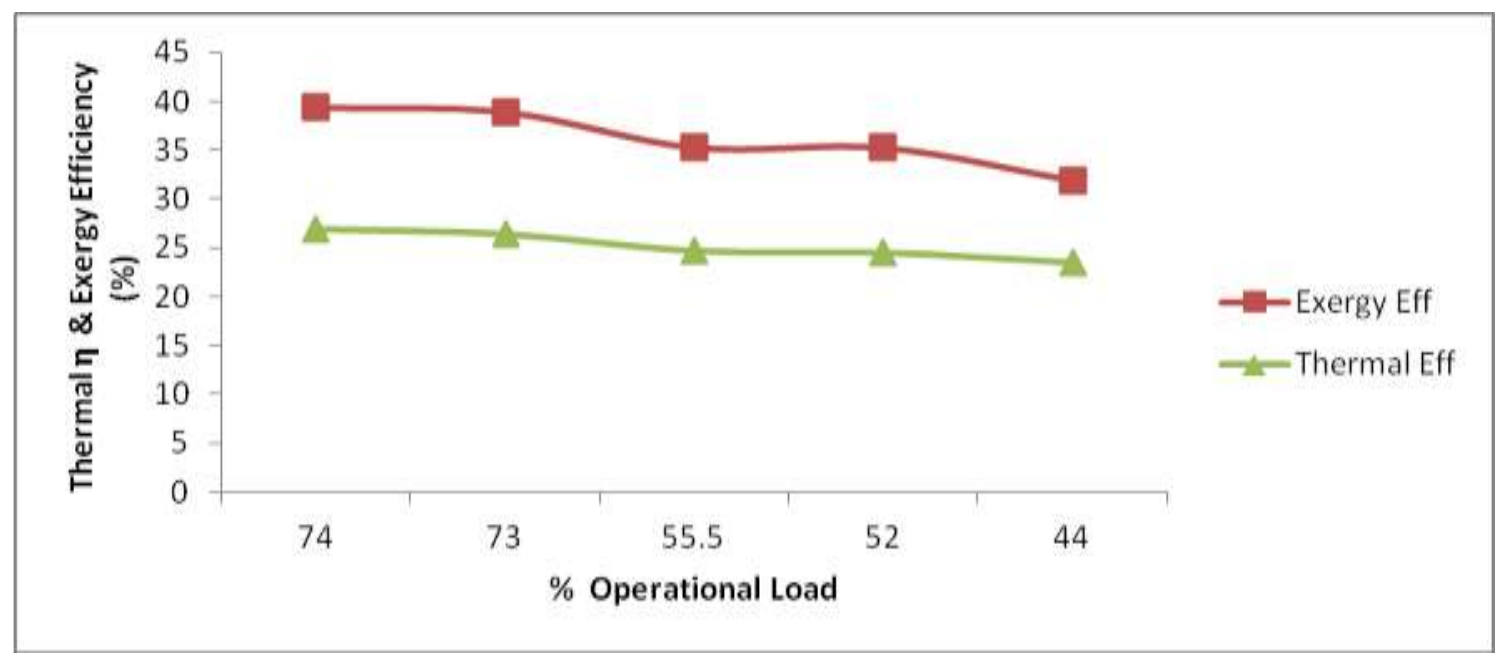

Fig. 2. Thermal and Exergy Efficiencies against \% Operational Load

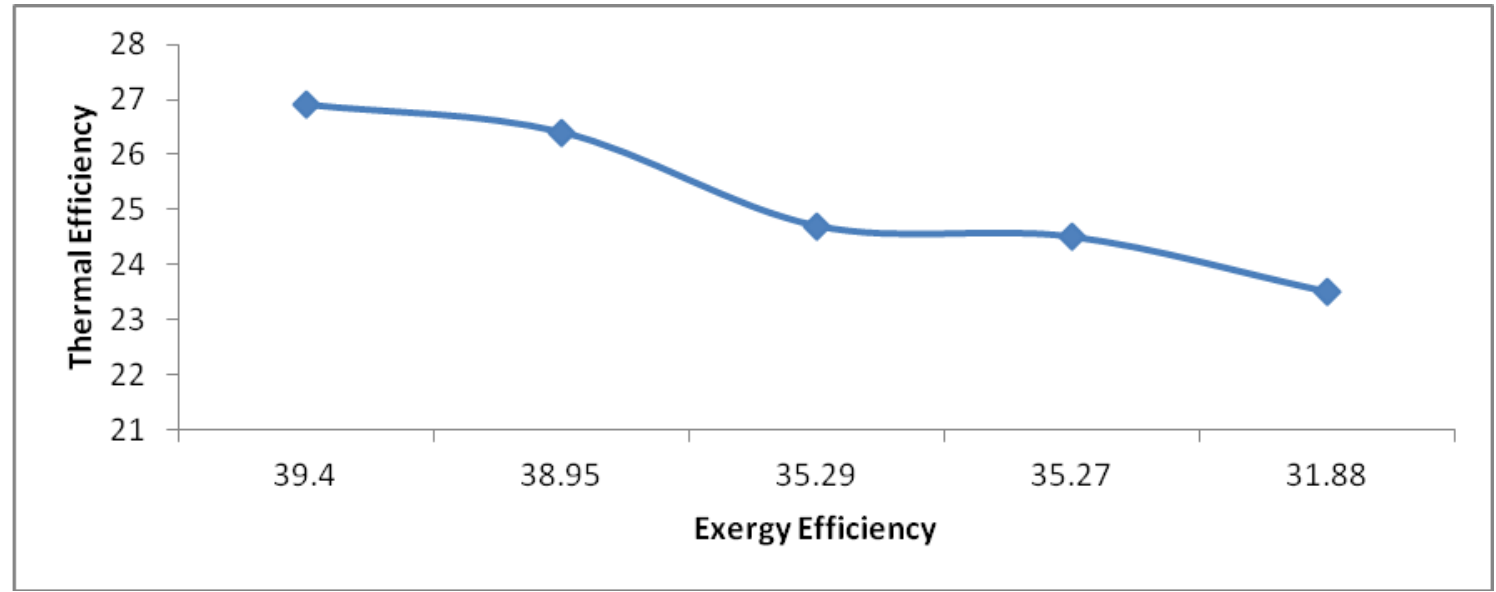

Figure 6. Thermal Efficiency against Exergy Efficiency 


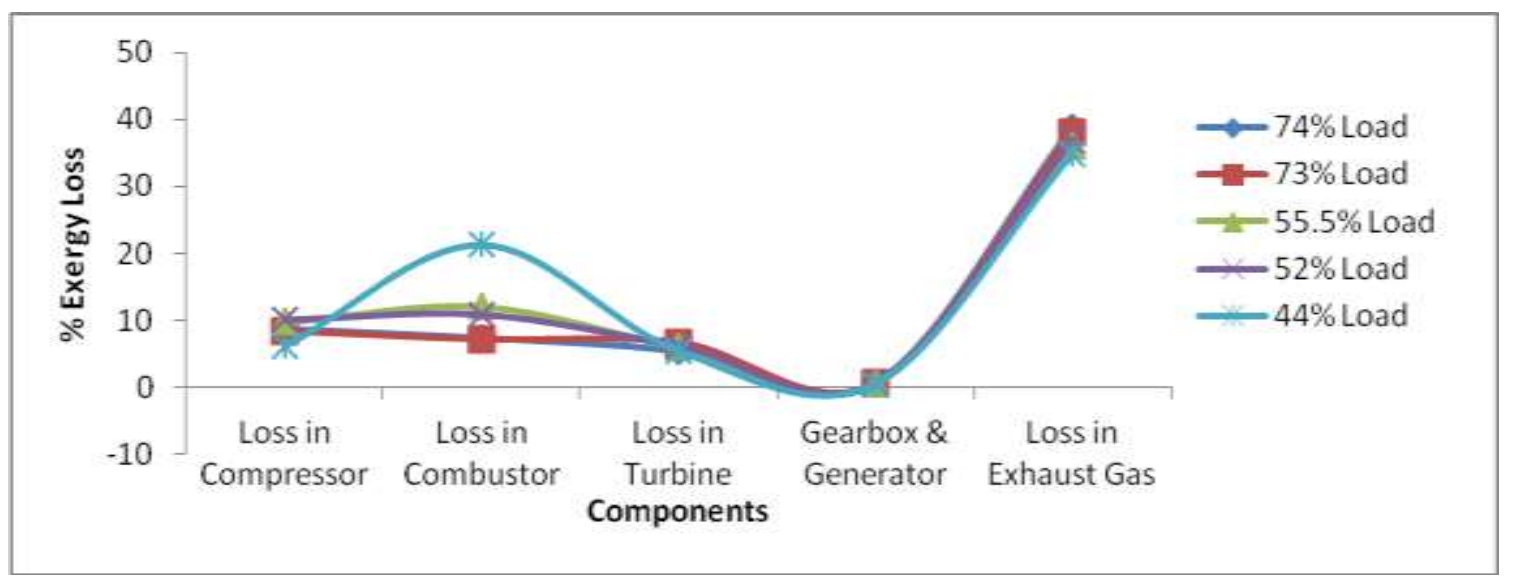

Figure 7. Percentage (\%) Exergy Loss across the Gas Turbine Components

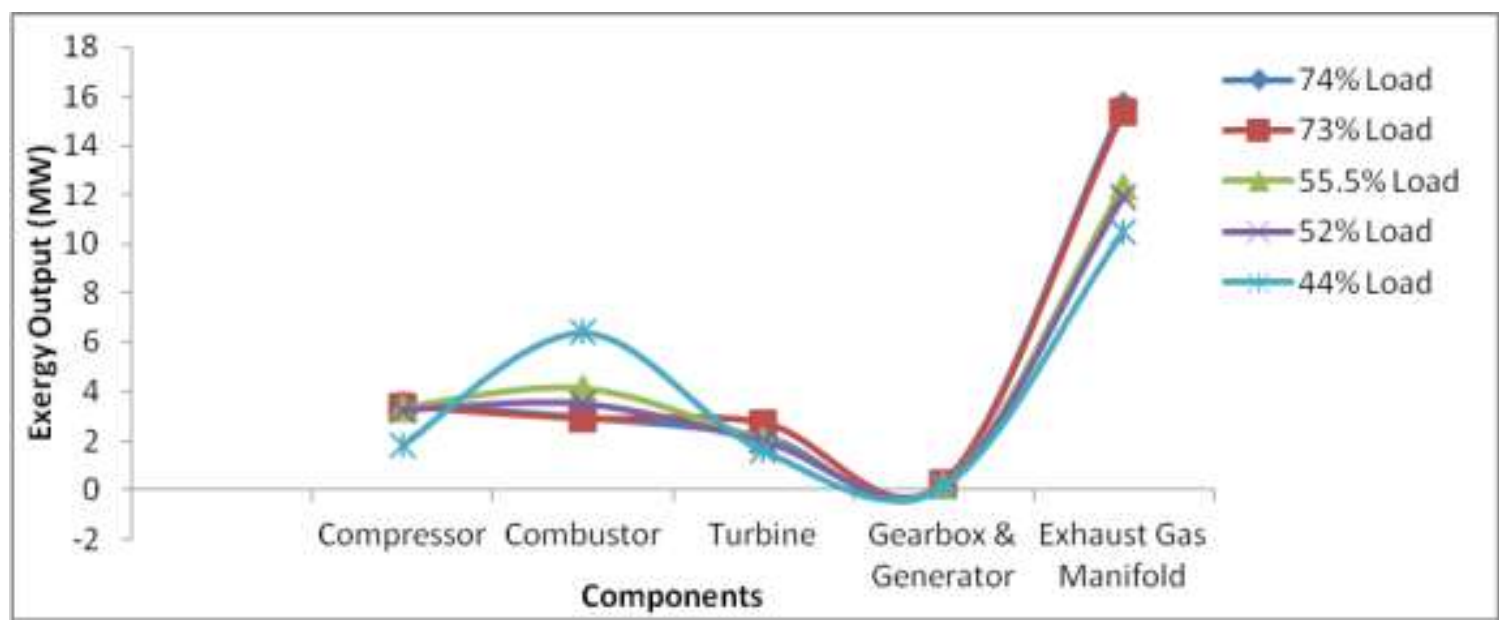

Figure 8. Exergy Output across the Gas Turbine Components

The performance indicators for turbines and compressor of the power plant have been assessed to check possible deviations from idealized ones based on exergy phenomenon. The results in Table 6 show that for every $1 \%$ drop in the operational load, thermal efficiency and exergy efficiency drop by $0.17 \%$ and $0.25 \%$ respectively. It further shows that there is about $0.006 \%$ decrease in fuel flow under the same conditions. Compressor isentropic efficiency ranges from 73 to $83 \%$. This could be attributed to inefficiency due to fuel and turbulence in the compression process. Back work ratio analysis shows that the compressor consumes $73 \%$ of the turbine energy output of $46 \%$ and $50 \%$ rated power output, which is higher than the bench mark value of $70 \%$.

The power plant has an overall exergy efficiency of about $34 \%$ for exergy output of 34MW generated. The analysis further showed that more than $35 \%$ of exergy was wasted in exhaust. The exergy lost as a result of irreversibility's in the compressive combustor and turbine at $73 \%$ and $74 \%$ rated power output was about $21 \%$, this value is small as compared to $38 \%$ of exergy wasted in the exhaust as shown by Fig. $5 \& 6$. At operational loads of $44 \%, 52 \%$ and $55.5 \%$, the combustor was the second largest component that degraded substantial amount of exergy, that is $21.3 \%, 11.9 \%$ and $12.1 \%$ of exergy were lost at $44 \%, 52 \%$ and $55.5 \%$ loads respectively.

\section{Conclusion}

The need to identify the source of inefficiencies and wastage of energy resources in energy conversion systems has necessitated this study. Exergy analysis has revealed the mechanisms which degrade the quality of the gas turbine system performance. All the components of the power plant degraded and wasted the quality of energy, with the combustor and the exhaust system leading in exergy destruction and wastages respectively. It is important to note that there was an appreciable decrease in exergy efficiency due to increase in irreversibility. Irreversibility varies with operation control and loading. The exergy wasted in exhaust gas was greater than the useful exergy in almost all the units. Waste heat recovery steam generator is therefore, a potential for energy saving.

Finally, components exergy degradation varies with operational condition and loading. Irreversibility is key factor that affect the performance of the power plant. 


\section{References}

Adumene, S., Le-ol, A. K., \& Amadi, R. K. C. (2015). Modeling Compressor's Initial Operating Conditions Effect on Turbine Performance in the Tropical Rainforest. American Journal of Engineering Research, 4(6), 80-88.

Anheden, M. (2002). Analysis of gas turbine systems for sustainable Energy Conversion. PhD Thesis, Royal Institute of Technology, Sweden.

Dincer, I., \& Cengel, Y. A. (2001). Energy, Entropy and Exergy Concepts and their roles in Thermal Engineering. Entropy, 3, 116-149. http://dx.doi.org/10.3390/e3030116

Ebadi, M. J., \& Gorgi-Bandy, M. (2005). Exergetic Analysis of Gas Turbine Plants. International Journal Exergy, 2(1), 31-39. http://dx.doi.org/10.1504/IJEX.2005.006431

Ertesvag, I. S., Kvamsdal, M. H., \& Bollard, O. (2004). Exergy Analysis of a gas turbine combined cycle power plant with precombustion $\mathrm{CO} 2$ Capture. Sintef Energy Research, Norway, 36.

Hermann, W. (2005). Quantifying Global Exergy Resources. Global Climate and Energy Project, 556Q, USA.

Hussain, M. M., Dincer, I., \& Zubair, S. M. (2004). A Feasibility Study of Using Thermal Energy Storage in a Conventional Air-Conditioning System. International Journal of Energy Research, 28(11), 955-967. http://dx.doi.org/10.1002/er.1006

Kotas, T. J. (1985). The Exergy method of thermal plant analysis Butterworth, London

Kwambai, B. C. (2005). Exergy Analysis of Olkaria I Geothermal Power Plant, Kenya. A Report on the Geothermal Training Program, United Nation University

Lebele-Alawa, B. T., \& Asuo, J. M. Exergy Analysis of Kolo Creek Gas Turbine Plant. Canadian Journal of Mechanical Science and Engineering, 2, 172-184.

Lebele-Alawa, B. T., \& Jo-Appah, V. (2015). Thermodynamic Performance Analysis of a Gas Turbine in an Equatorial Rain Forest Environment. Journal of Power and Energy Engineering, 3, 11-23. http://dx.doi.org/10.4236/jpee.2015.31002

Sue, D., \& Chuang, C. (2002). Engineering Design and Exergy Analysis of Combustion gas Turbine Based Power Generation System. Energy, 29, 1183-1205. http://dx.doi.org/10.1016/j.energy.2004.02.027

Suresh, M.V. J. J., Reddy, R. S., \& Kolar, A. J. (2006). Energy and Exergy Based Thermodynamic Analyis of a 62.5MW Coal-Based Thermal Power Plant- A case study. Indian Institute of Technology, Madras.

Verkhivker, G. P., \& Kosoy, B. V. (2001). On the Exergy Analysis of Power Plants, Energy Conversion and Management. http://dx.doi.org/10.1016/S0196-8904(00)00170-9

Wark, K., \& Richards, D. E. (1999) Thermodynamics, $6^{\text {th }}$ Ed. Mc Graw-Hill USA

\section{(cc) Br}

This work is licensed under a Creative Commons Attribution 3.0 License. 